\title{
Occurrence and Genetic Characteristics of Third-Generation Cephalosporin-Resistant Escherichia coli in Swiss Retail Meat
}

\author{
Debora Vogt, Gudrun Overesch,, Andrea Endimiani, ${ }^{2}$ Alexandra Collaud, \\ Andreas Thomann, and Vincent Perreten ${ }^{1}$
}

Prevalence and genetic relatedness were determined for third-generation cephalosporin-resistant Escherichia coli (3GC-R-Ec) detected in Swiss beef, veal, pork, and poultry retail meat. Samples from meat-packing plants (MPPs) processing 70\% of the slaughtered animals in Switzerland were purchased at different intervals between April and June 2013 and analyzed. Sixty-nine 3GC-R-Ec isolates were obtained and characterized by microarray, PCR/DNA sequencing, Multi Locus Sequence Typing (MLST), and plasmid replicon typing. Plasmids of selected strains were transformed by electroporation into E. coli TOP10 cells and analyzed by plasmid MLST. The prevalence of $3 \mathrm{GC}-\mathrm{R}-E c$ was $73.3 \%$ in chicken and $2 \%$ in beef meat. No $3 \mathrm{GC}-\mathrm{R}-E c$ were found in pork and veal. Overall, the bla $a_{\mathrm{CTX}-\mathrm{M}-1}(79.4 \%), b_{\mathrm{CMY}-2}(17.6 \%), \operatorname{bla}_{\mathrm{CMY}-4}(1.5 \%)$, and bla $a_{\mathrm{SHV}-12}(1.5 \%) \beta$-lactamase genes were detected, as well as other genes conferring resistance to chloramphenicol (cmlAl-like), sulfonamides (sul), tetracycline (tet), and trimethoprim $(d f r A)$. The 3GC-R-Ec from chicken meat often harbored virulence genes associated with avian pathogens. Plasmid incompatibility (Inc) groups IncI1, IncFIB, IncFII, and IncB/O were the most frequent. A high rate of clonality (e.g., ST1304, ST38, and ST93) among isolates from the same MPPs suggests that strains persist at the plant and spread to meat at the carcass-processing stage. Additionally, the presence of the $b l a_{\mathrm{CTX}-\mathrm{M}-1}$ gene on an IncI1 plasmid sequence type 3 (IncI1/pST3) in genetically diverse strains indicates interstrain spread of an epidemic plasmid. The $b l a_{\mathrm{CMY}-2}$ and $b l a_{\mathrm{CMY}-4}$ genes were located on IncB/O plasmids. This study represents the first comprehensive assessment of $3 \mathrm{GC}-\mathrm{R}-E c$ in meat in Switzerland. It demonstrates the need for monitoring contaminants and for the adaptation of the Hazard Analysis and Critical Control Point concept to avoid the spread of multidrug-resistant bacteria through the food chain.

\section{Introduction}

Ince the introduction of third-generation cephalosporins, a large number of extended-spectrum $\beta$-lactamase (ESBL), chromosomally mediated, and plasmid-mediated AmpC $\beta$-lactamase (cAmpC and pAmpC) producers have emerged in Gram-negative bacteria, particularly in Enterobacteriaceae such as Escherichia coli. ${ }^{14,49}$ ESBL enzymes belong to Ambler class A and are mainly represented by the SHV-, TEM-, and CTX-M-type families. The latter is the most frequent, with $\sim 150$ different types categorized into five groups. ${ }^{45,53}$ ESBLs hydrolyze penicillins, first- to fourthgeneration cephalosporins and monobactams, but they are inhibited by the standard $\beta$-lactamase inhibitors (e.g., clavulanate and tazobactam). Plasmid-mediated AmpC $\beta$-lactamases belong to Ambler class $\mathrm{C}$, hydrolyze penicillins and all cephalosporins (with the exception of the fourth-generation, e.g., cefepime), and are not inhibited by $\beta$-lactamase inhibitors. They are divided into six clusters, the most common being the CMY family. ${ }^{32}$

E. coli is a normal inhabitant of the gut of humans and animals; however, certain $E$. coli have acquired different virulence factors causing host-specific infections. Extraintestinal pathogenic E. coli (ExPEC) are responsible for colibacillosis in various animal species, including poultry (avian pathogenic $E$. coli $\left[\right.$ APEC]), ${ }^{19}$ urinary tract infections (uropathogenic E. coli), and newborn meningitis (newborn meningitis-causing $E$. coli) ${ }^{23}$ Enterotoxigenic $E$. coli can cause diarrhea in calves, ${ }^{27}$ pigs, ${ }^{24}$ and humans. Enterohemorrhagic E. coli (EHEC) can be commensal or pathogenic in cattle and have been of great interest as meat and vegetable contaminants, as they cause severe illness in humans. ${ }^{42,55} \mathrm{E}$. coli are also responsible for wound infections, pneumonia, and septicemia in people. ${ }^{14,25,49}$

\footnotetext{
${ }^{1}$ Vetsuisse Faculty, Institute of Veterinary Bacteriology, University of Bern, Bern, Switzerland.

${ }^{2}$ Faculty of Medicine, Institute for Infectious Diseases, University of Bern, Bern, Switzerland.
} 
The emergence of third-generation cephalosporin-resistant E. coli (3GC-R-Ec) isolates is associated with prolonged hospitalization, higher health costs, and mortality. ${ }^{41}$ In addition, $3 \mathrm{GC}-\mathrm{R}-E c$ can carry other antibiotic resistances, such as those against aminoglycosides, chloramphenicol, trimethoprim, tetracycline, sulfonamides, and quinolones. These genes are frequently located on the same genetic elements (e.g., plasmids, integrons) as the $b l a_{\mathrm{ESBL}}$ and $b l a_{\mathrm{pAmpC}}$ genes. It has been shown that these genetic elements can be transferred from commensals to pathogens and vice versa. ${ }^{41,49}$ This phenomenon was well demonstrated by Leverstein-van Hall et al., who found that in $19 \%$ of isolates from human patients, the plasmids containing the $b l a_{\mathrm{ESBL}}$ were indistinguishable from those isolated from poultry meat. ${ }^{39,49}$

Therefore, treating 3GC-R-Ec infections is becoming a challenge for clinicians and a growing concern for human health. Furthermore, the use of carbapenems to treat 3GC-R bacteria favors the selection of carbapenemase producers, which are able to hydrolyze carbapenems, leaving only colistin, fosfomycin, and tigecycline as last therapeutic options. ${ }^{44,49}$

Since the beginning of the 21 st century, ESBL- and pAmpC-producing isolates have been increasingly reported in livestock such as broilers, cattle, and pigs, but data about $3 \mathrm{GC}-\mathrm{R}-E c$ in meat are still scarce. 5,22,49 This situation raised public health and food safety concerns about whether foodproducing animals act as reservoirs for $3 \mathrm{GC}-\mathrm{R}-E c$, which may contaminate meat and thus reach consumers, where 3GC-R-Ec could transfer genetic elements to human pathogenic E. coli. ${ }^{16,37,40,49}$

In Switzerland, preliminary studies indicated a high prevalence of 3GC-R-Enterobacteriaceae in both indigenous and imported poultry meat. ${ }^{1,50}$ Another study recently showed a high rate of contamination of chicken meat received at a Swiss hospital kitchen. ${ }^{52}$ The aim of this study was to determine a more general and representative prevalence of 3GC-R-Ec in different lots of Swiss beef, pork, poultry, and veal retail meat and to determine their molecular characteristics. This study represents the first national surveillance of $3 \mathrm{GC}-\mathrm{R}-E c$ in meat, using a sampling plan based on representative production data from Swiss meat processing plants, and could therefore also serve as a basis for national monitoring of antibiotic resistance in fresh meat products at retail in Switzerland.

\section{Materials and Methods}

\section{Sampling}

Meat from meat-packing plants (MPPs) processing at least $70 \%$ of the slaughtered animals in Switzerland was analyzed in a time frame spanning from March 2013 to June 2013. This set encompasses a total of seven different MPPs, including two MPPs (MPPA and MPPB) processing solely poultry meat, four $\mathrm{MPPs}\left(\mathrm{MPPC}_{1}, \mathrm{MPPD}, \mathrm{MPPE}_{1}\right.$, and $\left.\mathrm{MPPF}_{1}\right)$ processing beef, three MPPs $\left(\mathrm{MPPC}_{2}, \mathrm{MPPE}_{2}\right.$, and $\left.\mathrm{MPPF}_{2}\right)$ processing pork, and three MPPs $\left(\mathrm{MPPC}_{3}, \mathrm{MPPE}_{3}\right.$, and MPPG) processing veal. One type of meat among chicken breast, pork, beef, and veal escalope was analyzed every 4 weeks to avoid sampling the same batch twice. Twenty-five chicken meat samples selected in different stores selling products from MPPA $(n=37)$ and MPPB $(n=38)$ were purchased three times at 4-week intervals for a total of 75 chicken breast samples. Twenty-five pork, beef, and veal escalopes were purchased twice at 4-week intervals from different stores selling meat from MPPC $(n=44)$, MPPD $(n=12), \operatorname{MPPE}(n=54), \operatorname{MPPF}(n=28)$, and MPPG $(n=12)$, for a total of 50 samples each.

\section{Isolation and identification of $3 G C-R-E C$}

Twenty-five grams of meat was homogenized in $25 \mathrm{ml}$ of LB broth in a stomacher (Stomacher 400 Circulator, Seward) for $1 \mathrm{~min}$ and incubated overnight at $37^{\circ} \mathrm{C}$ with agitation. A loop full $(10 \mu \mathrm{l})$ of this overnight culture was streaked onto MacConkey agar (Oxoid), Chrom ID ${ }^{\circledR}$ ESBL agar (bioMérieux), and Brilliance ${ }^{\mathrm{TM}} \mathrm{CRE}$ agar (Oxoid) selective plates and incubated overnight at $37^{\circ} \mathrm{C}$.

Lactose-positive colonies on MacConkey agar, reddish or white colonies on Chrom ID ESBL agar, and every colony growing on the Brilliance CRE agar plate were transferred onto Tryptone soy agar plates containing 5\% sheep blood (TSA-SB; Becton Dickinson) and incubated overnight at $37^{\circ} \mathrm{C}$. The colonies were identified using a matrix-assisted laser desorption/ionization time-of-flight mass spectrometer (MALDI-TOF MS, microflex LT; Bruker Daltonics). Isolates growing on Brilliance CRE agar plates were further tested by ertapenem (Becton Dickinson) disk diffusion tests according to the Clinical and Laboratory Standards Institute (CLSI) guidelines 2013. ${ }^{11}$

\section{Antimicrobial susceptibility testing}

Minimum inhibitory concentrations (MIC) were obtained by broth microdilution in cation adjusted Mueller-Hinton using ESB1F and EUMVS2 Sensititre ${ }^{\circledR}$ plates (TREK Diagnostic Systems). Interpretations of MIC were performed according to the CLSI guidelines. ${ }^{11}$

\section{Detection of antibiotic resistance and virulence factor genes}

DNA was obtained by incubating half a loop full of bacteria in $400 \mu \mathrm{l}$ of lysis buffer $(0.1 \mathrm{M}$ Tris- $\mathrm{HCl} \mathrm{pH} 8.5$, $0.05 \%$ Tween 20 and $0.24 \mathrm{mg} / \mathrm{ml}$ proteinase $\mathrm{K}$ ) for $45 \mathrm{~min}$ at $60^{\circ} \mathrm{C}$ followed by $15 \mathrm{~min}$ at $95^{\circ} \mathrm{C}$.

Antibiotic resistance and virulence factor genes were detected using AMR08 ArrayStrip ${ }^{\mathrm{TM}}$ microarrays (an upgrade of Card et al. $2013^{9}$ ) and the HybridisationPlus(+) Kit (Alere Technologies $\mathrm{GmbH}$ ). A signal intensity of 0.4 or higher was considered positive. The presence of $\beta$-lactam resistance genes $b l a_{\mathrm{SHV}}$ and $b l a_{\mathrm{TEM}}$, and virulence factor genes was confirmed by PCR and sequencing with already published primers. ${ }^{26,31,38,43,51}$ New primers were designed with the NCBI primer-Blast tool (www.ncbi.nlm.nih.gov/tools/primerblast): For the amplification and sequencing of the entire CTX-M Group 1 genes: CTX-M-Gr1 (CTX-MGr1_Fout2, 5'GACTATTCATGTTGTTGTTAWTTCG; CTX-MGr1-Rout, 5'-TTCCCCATTCCGTTTCCG [PCR and sequencing] and CTX-MGr1-FinSeq, 5'-CGCGTGATACCACTTCAC; CTXMGr1_RinSeq, 5'-CCGACTGCCGCTCTAATT [sequencing], [designed from consensus sequences obtained from the GenBank accession no. X92506, GQ274934, AY458016, JQ343850]). For cba (cba-F, 5'-AAGGCAGTGGAGTTTC TCCG; cba-R, 5'-AACGTTTTACCCAACGCAGC [GenBank accession no. NC_014382.1]), cif (cif-F, 5'-CCATGCA ACACACTTCAGCC; cif-R, 5'-GCTGCTCGAGCGATAG 
TGTC [GenBank accession no. AY128544.]), ireA (ireA-F, 5'-CACTGGGTAGCAGCATGGAA; ireA-R, 5'-TGAAGG AGCCCGAAATGCTT [GenBank accession no. NC_ 008563.1]), iroN (iroN-F, 5'-AGCCGGAAAGTAGCGATG AG; iroN-R, 5'-GACTTTGTCCCCAGTCCCAG [GenBank accession no. NC_011964.1]), and nleA (nleA-F. 5'-ACCGAG CCAAAAGACCCAAT; nleA-R, 5'-CTTGCCCAACCATTG CACC [GenBank accession no. NC_013008]). bla $a_{\mathrm{CMY}}$ genes were amplified using previously described primers and sequenced with both the recommended primers, ${ }^{36}$ and using an additional internal sequencing primer $b l a_{\mathrm{CMY}-2}$ IntF1 5'ACAACTTGACGCCGAAGC (GenBank accession no. X91840)].

Amino acid substitutions in the quinolone resistancedetermining region of $\mathrm{GyrA}$ and $\mathrm{ParC}$ were detected as described previously. ${ }^{7}$

PCR was performed using $5 \times \mathrm{HOT}_{\text {FIREPol }}{ }^{\circledR}$ Master Mix Ready to Load (Solis BioDyne) under the following conditions: initialization for $15 \mathrm{~min}$ at $94^{\circ} \mathrm{C}$ followed by 35 cycles of amplification for $30 \mathrm{~s}$ at $94^{\circ} \mathrm{C}, 30 \mathrm{~s}$ at $48-60^{\circ} \mathrm{C}$, and $1 \mathrm{~min}$ at $72^{\circ} \mathrm{C}$ and a final elongation step at $72^{\circ} \mathrm{C}$ for $5 \mathrm{~min}$. Selected DNA amplicons were sequenced using Big Dye by the Sanger method/chain termination method on an ABI Prism 3100 Genetic Analyzer (Applied Biosystems).

\section{Genotyping and determination of phylogenetic group}

Genotyping was performed by Multi Locus Sequence Typing (MLST) using the method described by Wirth et al. $2006^{56}$ and the sequence types (ST) were obtained with the database provided by the University College Cork, Ireland (http://mlst.ucc.ie/mlst/dbs/Ecoli). Plasmid incompatibility (Inc) groups were determined using a multiplex PCR-based replicon typing kit (PBRT kit MBK0038; Diatheva). Plasmids were extracted using the alkaline lysis method, including the phenol/chloroform purification step, ${ }^{47}$ and transformed into E. coli TOP10 cells by electroporation (Invitrogen). The transformants were selected on Mueller Hinton II agar containing either $70 \mathrm{mg} / \mathrm{L}$ of ampicillin or $2 \mathrm{mg} / \mathrm{L}$ cefotaxime and confirmed for the presence of $b l a_{\mathrm{CTX}-\mathrm{M}}$ and $b l a_{\mathrm{CMY}}$ genes by colony PCR. Inc groups of the transformed plasmids were confirmed by PCR using specific primers described previously. ${ }^{8}$ Plasmids of the IncI1 group were further typed by Plasmid MLST $^{28}$ and the STs were obtained using the PubMLST database (http://pubmlst.org/plasmid).

The phylogenetic groups of the isolates were obtained using the triplex PCR method previously described. ${ }^{10}$ The minimum spanning tree was constructed with Bionumerics 7.1 (Applied Maths).

\section{Statistical analysis}

Prevalence was calculated using $\mathrm{R}$ version 3.0.1 (The $\mathrm{R}$ foundation for Statistical Computing, www.r-project.org).

\section{Results}

\section{Prevalence}

The prevalences of $3 \mathrm{GC}-\mathrm{R}-E c$ were $73.3 \%$ (confidence interval [CI] 95\%: 62-83\%, $n=55 / 75)$ in chicken, $2 \%(\mathrm{CI}$ 95\%: $0-10 \%, n=1 / 50$ ) in beef, and 0\% (CI 95\%: $0-7.1 \%$, $n=0 / 50$ ) in pork and veal retail meat. No carbapenemresistant E. coli (Fig. 1) were detected, even for those colonies growing on Brilliance CRE agar. However, colonies containing CMY-2 $(n=8 / 9)$ and CTX-M-1 $(n=1 / 9)$ were found growing on this agar, as already reported. ${ }^{12}$

\section{$3 G C-R$-Ec isolates}

The only $3 \mathrm{GC}-\mathrm{R}-E c$ isolated from beef retail meat belonged to ST453, phylogenetic group B1, and it contained a $b l a_{\mathrm{CTX}-\mathrm{M}-1}$ gene as well as genes conferring resistance to sulfamethoxazole (sul2), tetracycline [tet(B)], and trimethoprim (dfrAl7) and a class 1 integrase as well as an IncIl plasmid (Table 1).

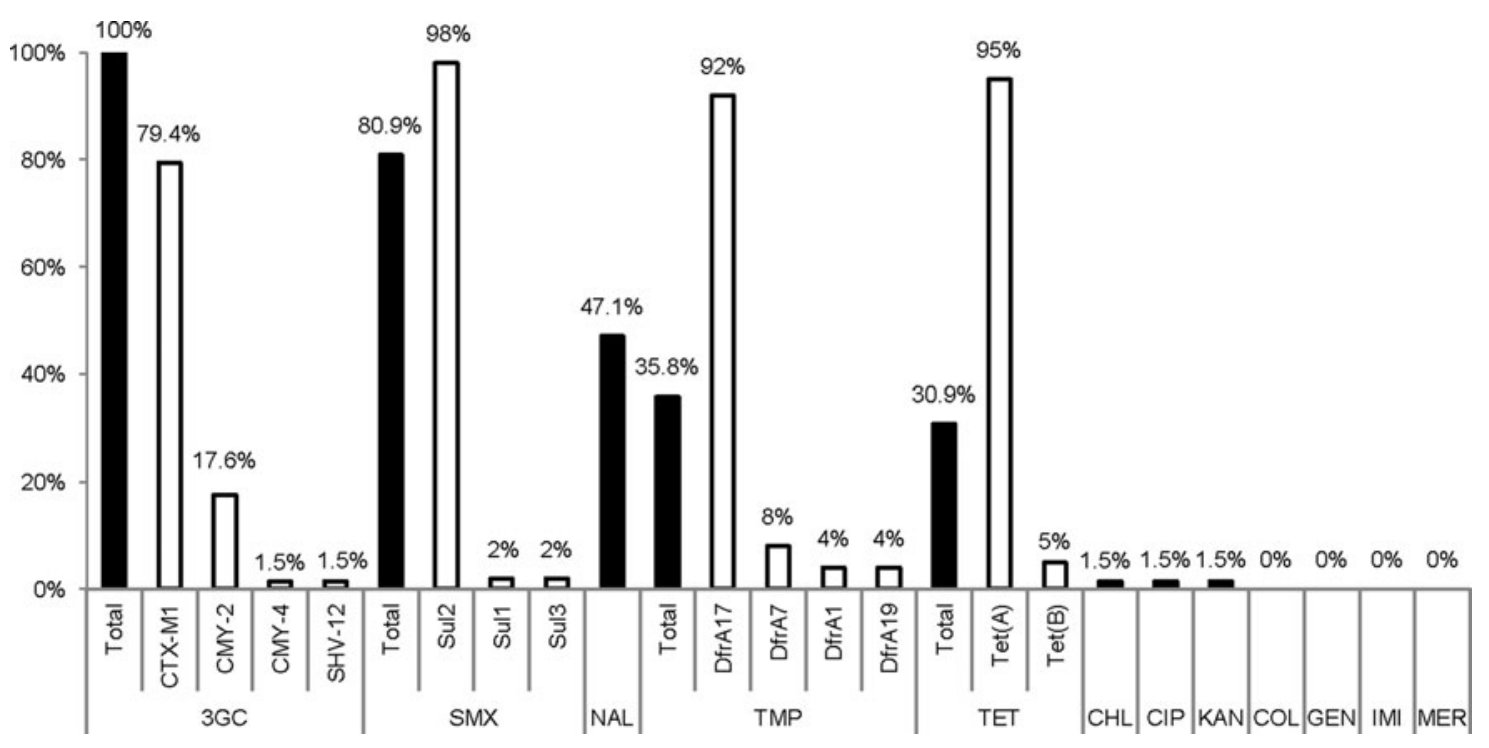

FIG. 1. Percentage of resistance and resistance determinants among isolates from chicken meat. 3GC, third-generation cephalosporins; CHL, chloramphenicol; CIP, ciprofloxacin; COL, colistin; GEN, gentamicin; IMI, imipenem; KAN, kanamycin; MER, meropenem; NAL, nalidixic acid; SMX, sulfamethoxazole; TET, tetracycline; TMP, trimethoprim; CMY, pAmpC $\beta$-lactamase; CTX-M-1, ESBL; SHV-12, ESBL; DfrA, dihydrofolate reductase for trimethoprim resistance; Sul, dihydropteroate synthetase for sulfonamide resistance; Tet, tetracycline efflux. 


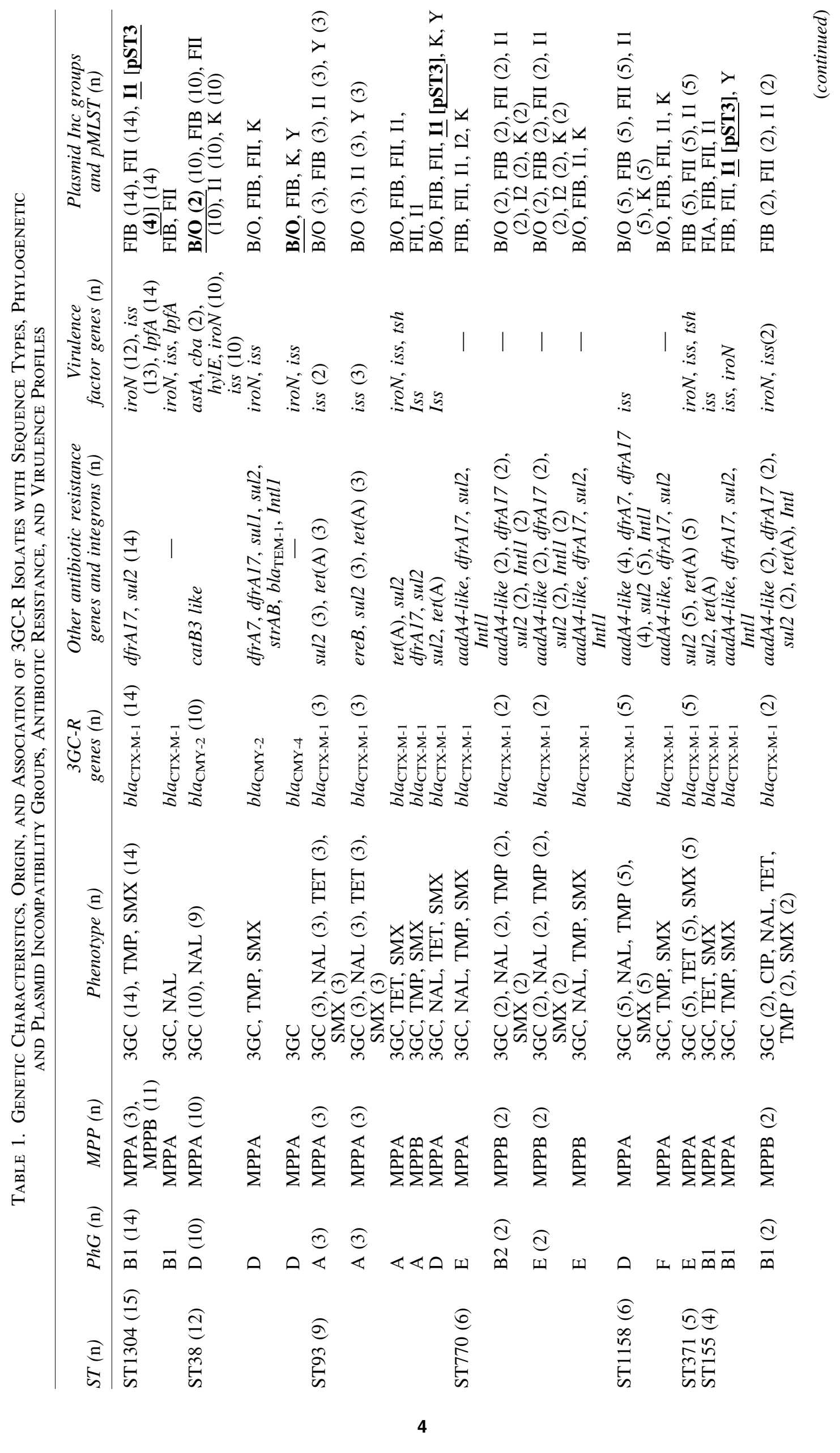




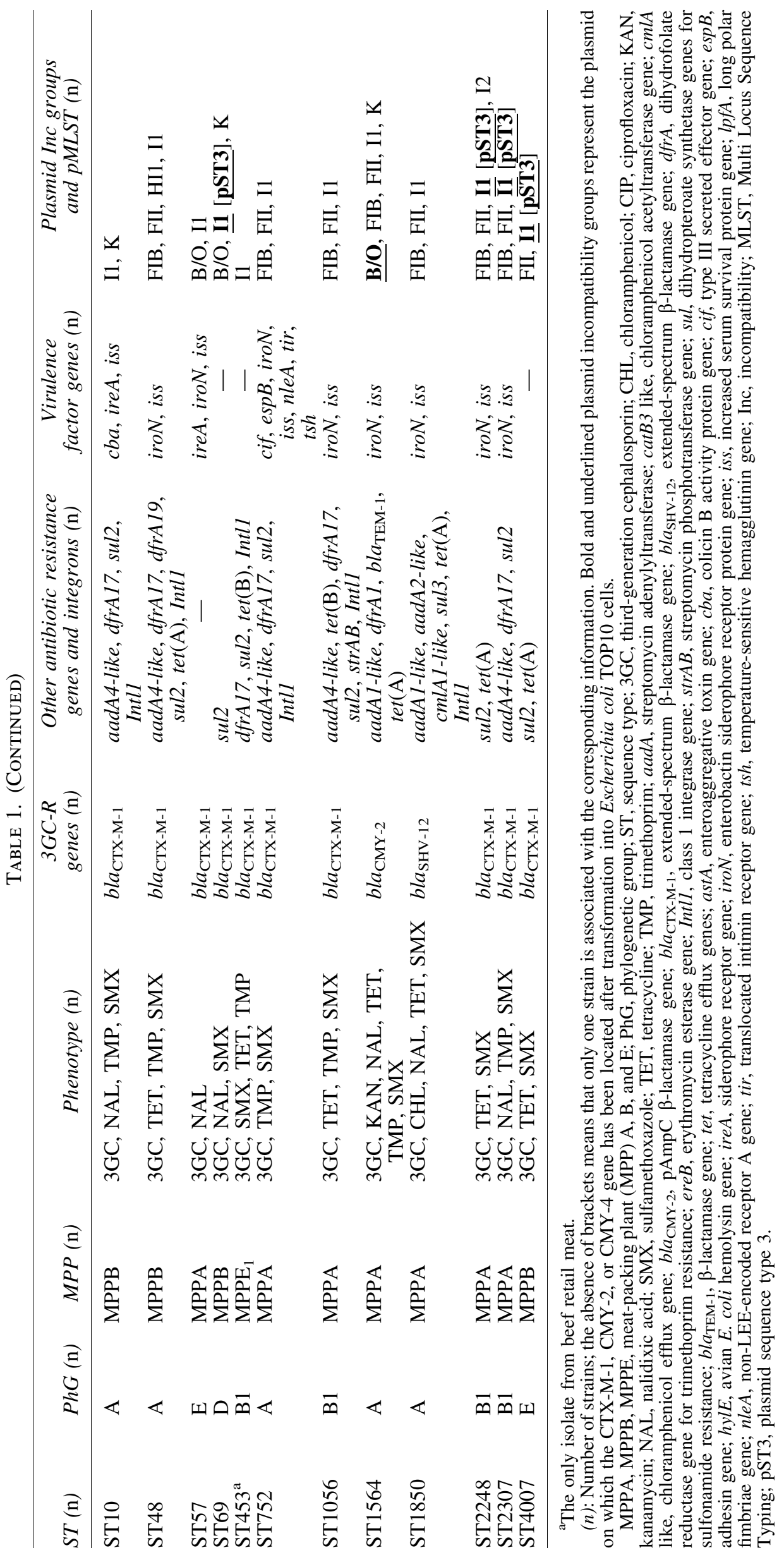


The 68 isolates from chicken retail meat (nine samples contained two and two samples contained three different STs) carried bla $a_{\mathrm{CTX}-\mathrm{M}-1}(79.4 \%)$, bla $a_{\mathrm{CMY}-2}(17.6 \%)$, bla $a_{\mathrm{CMY}-4}$ $(1.5 \%)$, or $b l a_{\mathrm{SHV}-12}(1.5 \%)$ and were frequently associated with additional resistance genes, such as sul sulfonamide resistance genes, $d f r A$ trimethoprim resistance genes, and tet tetracycline resistance genes (Fig. 1). Multidrug resistance was present in $61.8 \%$ of the isolates, which were resistant to three to six different antibiotics. The most frequent resistances were to third-generation cephalosporins, sulfamethoxazole, nalidixic acid, trimethoprim, and tetracycline (Fig. 1 and Table 1). One strain exhibited resistance to ciprofloxacin, which was associated to amino acid substitutions Ser83Leu, Asp87Asn in GyrA, and Ser80Arg in ParC.

The isolates from poultry belonged to 18 different STs, with the most frequent being ST1304 $(n=15)$, ST38 $(n=12)$, ST93 $(n=9)$, ST770 $(n=6)$, ST1158 $(n=6)$, ST371 $(n=5)$, and ST155 $(n=4)$ (Table 1). Isolates belonging to the same ST also belonged to the same phylogenetic group except for ST93 isolates that formed two different groups (Table 1). The bla $a_{\mathrm{SHV}-12}$ and $b l a_{\mathrm{CMY}-4}$ genes were each only present in one $\mathrm{ST}$, and $b l a_{\mathrm{CMY}-2}$ genes were present in two STs, whereas $b l a_{\text {CTX-M-1 }}$ was widespread in 15 different STs (Fig. 2). Isolates belonging to the same ST also contained the same resistance profiles and the same antibiotic resistance genes. Most of them also contained the same plasmid replicon types. The predominant Inc groups were IncI1 (91.2\%), IncFIB (83.8\%), IncFII (80.9\%), IncB/O (45.6\%), IncK (36.8\%), IncY $(11.8 \%)$, and IncI2 $(8.8 \%)$, whereas IncFIA, IncHI1, IncP, and IncX1 were only detected once (1.5\%) (Table 1). Plasmids belonging to IncI1 (98.1\%), IncFIB (85.2\%), and IncFII $(81.5 \%)$ were the most frequent in isolates harboring $b l a_{\mathrm{CTX}-\mathrm{M}-1}$, and the Inc groups IncB/O (100\%), IncFIB
$(100 \%)$, IncFII (100\%), IncK (100\%), and IncI1 $(83.3 \%)$ were most common in bla $a_{\mathrm{CMY}-2}$ carriers. Analysis of the

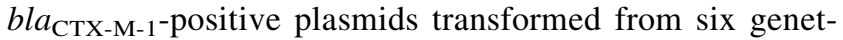
ically diverse strains (ST93, ST155, ST1304, ST2248, ST2307, and ST4007) as well as four genetically related strains (all of ST1304) into E. coli Top10 cells revealed that they all belonged to the IncI1 group and were of plasmid sequence type 3 (pST3). Similarly, the plasmids of three strains containing $b l a_{\mathrm{CMY}-2}$ (two strains belonging to ST38 and one to ST1564) as well as of one strain containing bla CMY-4 $_{\mathrm{CMT} 38)}$ all belonged to the IncB/O group as determined by PCR (Table 1 and Fig. 2).

\section{Virulence factors}

A total of 12 different virulence factor genes could be identified from the isolates (Table 1). The APEC-associated iroN and iss genes were found in $59.4 \%$ and $76.8 \%$ of the isolates, respectively; in $59.4 \%$ of the isolates, they were detected together. Other APEC-associated virulence genes, including $t s h$, ast $A$, and $h y l E$, were found less frequently $(<4.3 \%)$. The lpfA (long polar fimbriae) gene was only detected in one predominant clonal lineage ST1304 (100\%). One strain belonging to ST752 contained enteropathogenic E. coli (EPEC)/EHEC-associated virulence factor genes $c i f$, $e s p B$, nleA, and tir additionally to iss, iroN, and $t s h$. The isolates belonged to different phylogenetic groups; A: $18.8 \%$, B1: $33.3 \%, \mathrm{~B} 2: 2.9 \%, \mathrm{D}: 27.5 \%$, E: $15.9 \%$, and F: $1.4 \%$ (Table 1).

\section{Discussion}

A very high prevalence (i.e., $73.3 \%$ ) of 3GC-R-Ec was found at retail in poultry meat from indigenous animal

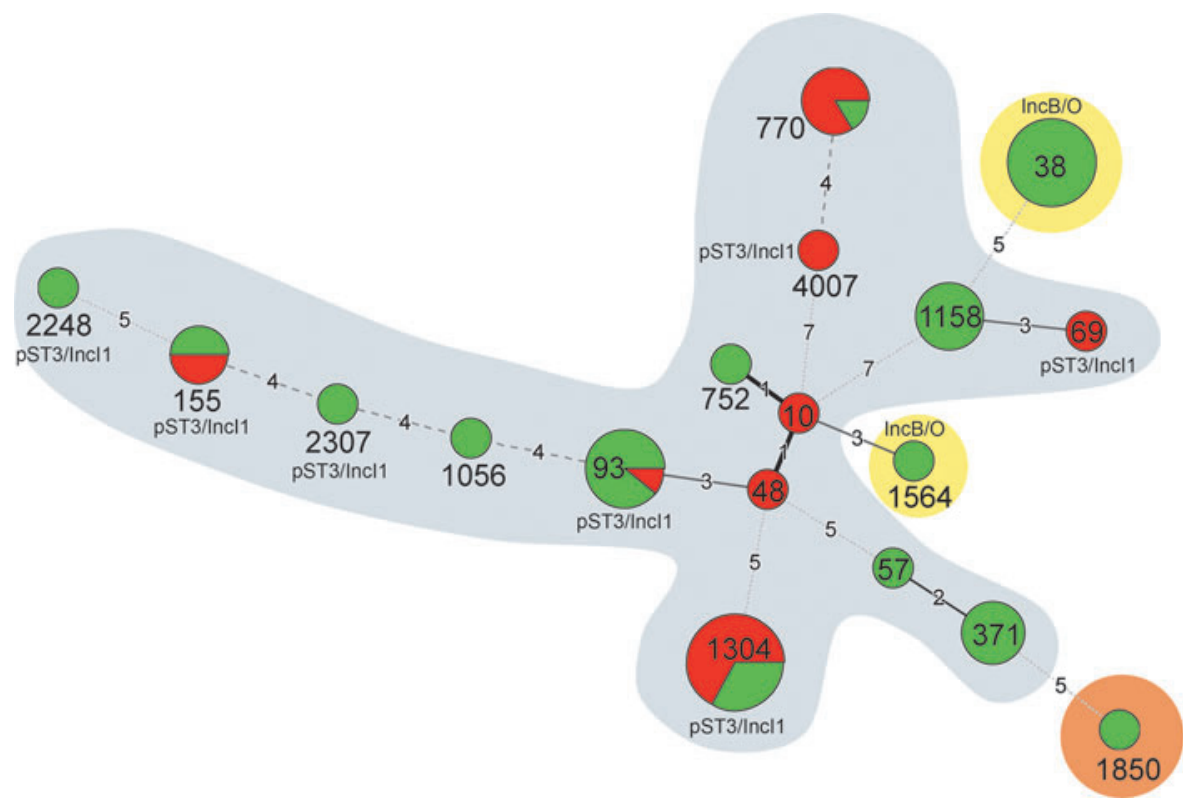

FIG. 2. Minimum spanning tree of the $3 \mathrm{GC}-\mathrm{R}-E c$ isolates from chicken retail meat. Each circle represents one sequence type (ST), and the size of the circle reflects the number of isolates belonging to a particular ST. Plasmid sequence type 3 (pST3) and incompatibility groups (IncI1 and IncB/O) are indicated if detected within an ST. Lines between the circles indicate the relationships between the different STs. Green: STs found on samples from MPPA, Red: STs found on samples

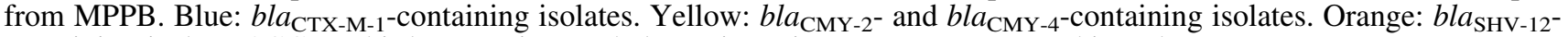
containing isolate. 3GC-R, third-generation cephalosporin resistant; MPP, meat-packing plant. 
production in Switzerland, whereas beef $(2 \%)$, pork $(0 \%)$, and veal $(0 \%)$ meats were less or not contaminated. The same observation has already been made for meat destined for hospital meals in Switzerland as well as in other countries. $^{4,5,17,52}$ However, the analysis of meat packed in two different MPPs and purchased at different time points indicates that contamination is not a sporadic event, but likely occurs during slaughter and meat processing (Table 2). Indeed, the prevalence of 3GC-R-Ec in Swiss poultry meat is higher as that observed in Swiss broiler herds (38\%). ${ }^{6}$ The high rate of clonality for samples from the same slaughterhouse found here underlines the possible spread and persistence of bacteria in meat packing plants, whereas 3GC-R-Ec containing CTX-M-1 from broilers are very diverse. ${ }^{21}$

Swiss meat contained CTX-M-1-, CMY-2-, and SHV-12possessing E. coli, which are also the most frequent 3GC-R$E c$ detected in animals in Switzerland and Europe. ${ }^{49}$ The E. coli also belong to the ST commonly detected among poultry isolates (ST10, ST48, ST57, ST69, ST93, ST155, ST770, and ST1304) around Europe and in Switzerland ${ }^{49,50}$ (personal communication). Similarly to other studies, isolates from poultry meat harboring $b l a_{\mathrm{CTX}-\mathrm{M}-1}$ were mainly associated with the presence of IncI1 plasmids, and those containing bla $a_{\mathrm{SHV}-12}$ with IncFIB, IncFII, and IncI1 plasmids. ${ }^{2,18,20,28,49,54}$ The $b l a_{\mathrm{CMY}-2}$ and $b l a_{\mathrm{CMY}-4}$ genes were associated with IncB/O plasmids, which is uncommon. In fact, the association of $b l a_{\mathrm{CMY}-2}$ with $\mathrm{IncB} / \mathrm{O}$ plasmids has only been recently reported in $E$. coli isolates from broilers in Japan ${ }^{30}$ while $b l a_{\mathrm{CMY}-2}$ has mainly been associated with IncK and IncF1 plasmids in other European countries. ${ }^{2,20,54}$ This suggests that a particular CMY-2 plasmid has been selected and is circulating among E.coli of the Swiss poultry meat production. Of note, all the CTX-M-1-expressing plasmids analyzed belonged to IncI1/pST3, an epidemic plasmid propagating in Enterobacteriaceae from different human and animal sources, including poultry in several European countries (plasmid MLST isolate database [http:// pubmlst.org/databases]). ${ }^{2,15,28,29}$ In our study, the $b l a_{\text {CTX-M-1- }}{ }^{-}$ containing IncI1/pST3 plasmid was detected in both genetically related and genetically diverse E. coli strains, further emphasizing the interstrain exchange of this promiscuous plasmid in the poultry meat production.

The detection of chicken-associated toxins in the 3GC-R$E c$ emphasizes that the isolates originated from poultry. Indeed, the predominant virulence factors iroN and iss as well as tsh have been associated with plasmids in APEC, principally ColV and ColBM from the IncFIB group, ${ }^{33}$ and also with plasmids of the IncB/O, IncFII, IncI1, and IncP groups. ${ }^{35}$ Such Inc groups were also frequent in isolates from Swiss poultry meat. The iroN und iss genes are located on a conserved region, whereas $t s h$ is on a more variable portion of the putative virulence region of the plasmid and may be absent, explaining the lower frequency of $t s h$ found here. ${ }^{34}$ This large virulence plasmid (ColV) has also been found in other ExPEC but to a lesser extent. ${ }^{19}$ The role of such virulence factors has not yet been fully understood in human infections. ${ }^{23}$ However, two isolates (ST752 and ST1304) harbor the virulence factor genes (cif, $\operatorname{esp} B, \operatorname{lpf} A$, nleA, and tir) that have been associated with human EHEC/EPEC (Table 1). ${ }^{3}$ Additionally, chicken meat was found to contain 3GC-R-Ec, which belonged to the same STs and contained the same cephalosporinase genes (ST69/CMY-2, ST10/CTX-M-1, and ST453/CTX$\mathrm{M}-1)$ as some of those causing infections in humans in Switzerland, ${ }^{48}$ suggesting a possible transmission of 3GC$\mathrm{R}-E c$ from retail meat to humans. Such a phenomenon has already been observed in the Netherlands, where patients, retail chicken meat, and poultry were shown to share the same ESBL genes, plasmids, and strains. ${ }^{22}$

Nevertheless, the pandemic strain ST131 carrying bla $a_{\mathrm{CTX}-\mathrm{M}-15}$, which is responsible for most ESBL-producing human infections in Europe ${ }^{46,49}$ and in Switzerland, ${ }^{48}$ has not yet been found in meat produced in Switzerland, ${ }^{21,49}$ although it has been detected in a chicken farm in Spain. ${ }^{13}$

Even if no isolate with the typical characteristics of the most prevalent human ST131/CTX-M-15 was detected during this study, a worrisome high rate of $3 \mathrm{GC}-\mathrm{R}-E c$ was detected in retail chicken meat originating from indigenous broiler production. Of further concern, this observation included isolates with human infection-associated STs, as well as those containing genes contributing to pathogenicity on humans, and the presence of an epidemic bla $_{\mathrm{CTX}-\mathrm{M}-1}$-containing plasmid known to be widespread in Enterobacteriaceae from both animal and human origin.

The presence of such multidrug-resistant bacteria with pathogenic potential in meat should be avoided. This goal could be achieved by adopting the Hazard Analysis and Critical Control Point and continuously monitoring concepts along the entire meat production chain up to retail, to track back sources of microbial contamination, and by implementing stricter hygiene concepts to stop the cascade of multidrug-resistant bacteria before they reach consumers.

Table 2. Distribution of Sequence Types from Chicken Meat Over the Sampling Weeks Among the Meat-Packing Plants A and B

\begin{tabular}{|c|c|c|c|c|c|c|c|}
\hline \multirow[b]{2}{*}{$S T(\mathrm{n})$} & \multicolumn{3}{|c|}{ Sampling week } & \multirow[b]{2}{*}{$S T(\mathrm{n})$} & \multicolumn{3}{|c|}{ Sampling week } \\
\hline & $W 1(\mathrm{n})$ & W5 (n) & $W 9$ (n) & & $W 1(\mathrm{n})$ & $W 5(\mathrm{n})$ & W9 (n) \\
\hline ST1304 (15) & A (1) & A (2), B (11) & A (1) & ST57 (1) & & & A (1) \\
\hline ST38 (12) & A (6) & & A (6) & ST69 (1) & & B (1) & \\
\hline ST93 (9) & B (1) & & A (8) & ST752 (1) & & A (1) & \\
\hline ST770 (6) & A (1), B (5) & & & ST1056 (1) & & A (1) & \\
\hline ST1158 (6) & & A (6) & & ST1564 (1) & A (1) & & \\
\hline ST371 (5) & & & A (5) & ST1850 (1) & & & A (1) \\
\hline ST155 (4) & B (1) & A (1), B (1) & A (1) & ST2248 (1) & & A (1) & \\
\hline ST10 (1) & B (1) & & & ST2307 (1) & & A (1) & \\
\hline ST48 (1) & B (1) & & & ST4007 (1) & & & B (1) \\
\hline
\end{tabular}




\section{Acknowledgments}

The authors thank Susanne Rickli, Salome N. Seiffert, Christian Strauss, and Cindy Dierikx for assistance or advice. This project was supported by grant 1.13.20 from the Swiss Veterinary Federal Office (BVET).

\section{Disclosure Statement}

None to declare.

\section{References}

1. Abgottspon, H., R. Stephan, C. Bagutti, P. Brodmann, H. Hächler, and K. Zurfluh. 2014. Characteristics of extendedspectrum cephalosporin-resistant Escherichia coli isolated from Swiss and imported poultry meat. J. Food Prot. 77: $112-115$.

2. Accogli, M., D. Fortini, M. Giufre, C. Graziani, M. Dolejska, A. Carattoli, and M. Cerquetti. 2013. IncI1 plasmids associated with the spread of CMY-2, CTX-M-1 and SHV-12 in Escherichia coli of animal and human origin. Clin. Microbiol. Infect. 19:E238-E240.

3. Afset, J.E., G. Bruant, R. Brousseau, J. Harel, E. Anderssen, L. Bevanger, and K. Bergh. 2006. Identification of virulence genes linked with diarrhea due to atypical enteropathogenic Escherichia coli by DNA microarray analysis and PCR. J. Clin. Microbiol. 44:3703-3711.

4. Agersø, Y., F.M. Aarestrup, K. Pedersen, A.M. Seyfarth, T. Struve, and H. Hasman. 2012. Prevalence of extended-spectrum cephalosporinase (ESC)-producing Escherichia coli in Danish slaughter pigs and retail meat identified by selective enrichment and association with cephalosporin usage. J. Antimicrob. Chemother. 67:582-588.

5. Börjesson, S., M. Egervärn, M. Lindblad, and S. Englund. 2013. Frequent occurrence of extended-spectrum $\beta$-lactamase- and transferable AmpC $\beta$-lactamase-producing Escherichia coli on domestic chicken meat in Sweden. Appl. Environ. Microbiol. 79:2463-2466.

6. Büttner, S., S. Flurina, C. Müntener, M. Jäggi, and G. Overesch. 2013. Bericht über den Vertrieb von Antibiotika in der Veterinärmedizin und das Antibiotikaresistenzmonitoring bei Nutztieren in der Schweiz (ARCH-VET 2012). Federal Veterinary Office and Swissmedic, Bern, Switzerland. Available at www.swissmedic.ch/archvet-d.asp. (Online.)

7. Cano, M.E., J.M. Rodriguez-Martinez, J. Agüero, A. Pascual, J. Calvo, J.M. García-Lobo, C. Velasco, M.V. Francia, and L. Martinez-Martinez. 2009. Detection of plasmid-mediated quinolone resistance genes in clinical isolates of Enterobacter spp. in Spain. J. Clin. Microbiol. 47:2033-2039.

8. Carattoli, A., A. Bertini, L. Villa, V. Falbo, K.L. Hopkins, and E.J. Threlfall. 2005. Identification of plasmids by PCR-based replicon typing. J. Microbiol. Methods 63:219-228.

9. Card, R., J. Zhang, P. Das, C. Cook, N. Woodford, and M.F. Anjum. 2013. Evaluation of an expanded microarray for detecting antibiotic resistance genes in a broad range of gram-negative bacterial pathogens. Antimicrob. Agents. Chemother. 57:458-465.

10. Clermont, O., J.K. Christenson, E. Denamur, and D.M. Gordon. 2013. The Clermont Escherichia coli phylo-typing method revisited: improvement of specificity and detection of new phylo-groups. Environ. Microbiol. Rep. 5:58-65.
11. Clinical and Laboratory Standards Institute. 2013. Performance Standards for Antimicrobial Susceptibility Testing; twenty-third informational supplement M100-S23, vol. 33, no. 1. Clinical and Laboratory Standards Institute, Wayne, PA.

12. Cohen, S.J., G. Voets, W. Rottier, S. Voskuil, J. Scharringa, K. Van Dijk, A.C. Fluit, and M. Leverstein-Van Hall. 2013. Evaluation of the Oxoid Brilliance CRE Agar for the detection of carbapenemase-producing Enterobacteriaceae. Eur. J. Clin. Microbiol. Infect. Dis. 32: 1445-1449.

13. Cortés, P., V. Blanc, A. Mora, G. Dahbi, J.E. Blanco, M. Blanco, C. López, A. Andreu, F. Navarro, M.P. Alonso, G. Bou, J. Blanco, and M. Llagostera. 2010. Isolation and characterization of potentially pathogenic antimicrobialresistant Escherichia coli strains from chicken and pig farms in Spain. Appl. Environ. Microbiol. 76:2799-2805.

14. D'Andrea, M.M., F. Arena, L. Pallecchi, and G.M. Rossolini. 2013. CTX-M-type $\beta$-lactamases: a successful story of antibiotic resistance. Int. J. Med. Microbiol. 303: 305-317.

15. Dahmen, S., M. Haenni, and J.Y. Madec. 2012. IncI1/ST3 plasmids contribute to the dissemination of the $b l a_{\mathrm{CTX}-\mathrm{M}-1}$ gene in Escherichia coli from several animal species in France. J. Antimicrob. Chemother. 67:3011-3012.

16. Dierikx, C.M., J.A. van der Goot, H.E. Smith, A. Kant, and D.J. Mevius. 2013. Presence of ESBL/AmpC-producing Escherichia coli in the broiler production pyramid: a descriptive study. PLoS One 8: 79005.

17. Doi, Y., D.L. Paterson, P. Egea, A. Pascual, L. LópezCerero, M.D. Navarro, J.M. Adams-Haduch, Z.A. Qureshi, H.E. Sidjabat, and J. Rodriguez-Bano. 2010. Extended-spectrum and CMY-type $\beta$-lactamase-producing Escherichia coli in clinical samples and retail meat from Pittsburgh, USA and Seville, Spain. Clin. Microbiol. Infect. 16:33-38.

18. Dolejska, M., M. Matulova, L. Kohoutova, I. Literak, J. Bardon, and A. Cizek. 2011. Extended-spectrum $\beta$-lactamase-producing Escherichia coli in turkey meat production farms in the Czech Republic: national survey reveals widespread isolates with $b l a_{\mathrm{SHV}-12}$ genes on IncFII plasmids. Lett. Appl. Microbiol. 53:271-277.

19. Dziva, F., and M.P. Stevens. 2008. Colibacillosis in poultry: unravelling the molecular basis of virulence of avian pathogenic Escherichia coli in their natural hosts. Avian Pathol. 37:355-366.

20. Egervärn, M., S. Börjesson, S. Byfors, M. Finn, C. Kaipe, S. Englund, and M. Lindblad. 2014. Escherichia coli with extended-spectrum $\beta$-lactamases or transferable AmpC $\beta$-lactamases and Salmonella on meat imported into Sweden. Int. J. Food Microbiol. 171:8-14.

21. Endimiani, A., A. Rossano, D. Kunz, G. Overesch, and V. Perreten. 2012. First countrywide survey of third-generation cephalosporin-resistant Escherichia coli from broilers, swine, and cattle in Switzerland. Diagn. Microbiol. Infect. Dis. 73:31-38.

22. Ewers, C., A. Bethe, T. Semmler, S. Guenther, and L.H. Wieler. 2012. Extended-spectrum $\beta$-lactamase-producing and AmpC-producing Escherichia coli from livestock and companion animals, and their putative impact on public health: a global perspective. Clin. Microbiol. Infect. 18: 646-655.

23. Ewers, C., G. Li, H. Wilking, S. Kiessling, K. Alt, E.M. Antao, C. Laturnus, I. Diehl, S. Glodde, T. Homeier, U. 
Böhnke, H. Steinruck, H.C. Philipp, and L.H. Wieler. 2007. Avian pathogenic, uropathogenic, and newborn meningitis-causing Escherichia coli: how closely related are they? Int. J. Med. Microbiol. 297:163-176.

24. Fairbrother, J.M., E. Nadeau, and C.L. Gyles. 2005. Escherichia coli in postweaning diarrhea in pigs: an update on bacterial types, pathogenesis, and prevention strategies. Anim. Health Res. Rev. 6:17-39.

25. Falagas, M.E., and D.E. Karageorgopoulos. 2009. Extended-spectrum $\beta$-lactamase-producing organisms. J. Hosp. Infect. 73:345-354.

26. Feizabadi, M.M., S. Delfani, N. Raji, A. Majnooni, M. Aligholi, F. Shahcheraghi, M. Parvin, and D. Yadegarinia. 2010. Distribution of $b l a_{\mathrm{TEM}}, b l a_{\mathrm{SHV}}, b l a_{\mathrm{CTX}-\mathrm{M}}$ genes among clinical isolates of Klebsiella pneumoniae at Labbafinejad Hospital, Tehran, Iran. Microb. Drug. Resist. 16:49-53.

27. Foster, D.M., and G.W. Smith. 2009. Pathophysiology of diarrhea in calves. Vet. Clin. North Am. Food Anim. Pract. 25:13-36, xi.

28. García-Fernández, A., G. Chiaretto, A. Bertini, L. Villa, D. Fortini, A. Ricci, and A. Carattoli. 2008. Multilocus sequence typing of IncI1 plasmids carrying extendedspectrum $\beta$-lactamases in Escherichia coli and Salmonella of human and animal origin. J. Antimicrob. Chemother. 61:1229-1233.

29. Girlich, D., L. Poirel, A. Carattoli, I. Kempf, M.F. Lartigue, A. Bertini, and P. Nordmann. 2007. Extendedspectrum $\beta$-lactamase CTX-M-1 in Escherichia coli isolates from healthy poultry in France. Appl. Environ. Microbiol. 73:4681-4685.

30. Hiki, M., M. Usui, A. Kojima, M. Ozawa, Y. Ishii, and T. Asai. 2013. Diversity of plasmid replicons encoding the bla $a_{\mathrm{CMY}-2}$ gene in broad-spectrum cephalosporin-resistant Escherichia coli from livestock animals in Japan. Foodborne Pathog. Dis. 10:243-249.

31. Hujer, K.M., A.M. Hujer, E.A. Hulten, S. Bajaksouzian, J.M. Adams, C.J. Donskey, D.J. Ecker, C. Massire, M.W. Eshoo, R. Sampath, J.M. Thomson, P.N. Rather, D.W. Craft, J.T. Fishbain, A.J. Ewell, M.R. Jacobs, D.L. Paterson, and R.A. Bonomo. 2006. Analysis of antibiotic resistance genes in multidrug-resistant Acinetobacter $s p$. isolates from military and civilian patients treated at the Walter Reed Army Medical Center. Antimicrob. Agents Chemother. 50:4114-4123.

32. Jacoby, G.A. 2009. AmpC $\beta$-lactamases. Clin. Microbiol. Rev. 22:161-82.

33. Johnson, T.J., S.J. Johnson, and L.K. Nolan. 2006. Complete DNA sequence of a ColBM plasmid from avian pathogenic Escherichia coli suggests that it evolved from closely related ColV virulence plasmids. J. Bacteriol. 188:5975-5983.

34. Johnson, T.J., K.E. Siek, S.J. Johnson, and L.K. Nolan. 2006. DNA sequence of a ColV plasmid and prevalence of selected plasmid-encoded virulence genes among avian Escherichia coli strains. J. Bacteriol. 188: 745-758.

35. Johnson, T.J., Y.M. Wannemuehler, S.J. Johnson, C.M. Logue, D.G. White, C. Doetkott, and L.K. Nolan. 2007. Plasmid replicon typing of commensal and pathogenic Escherichia coli isolates. Appl. Environ. Microbiol. 73: 1976-1983.

36. Jørgensen, R.L., J.B. Nielsen, A. Friis-Møller, H. Fjeldsoe-Nielsen, and K. Schønning. 2010. Prevalence and molecular characterization of clinical isolates of $E s$ cherichia coli expressing an AmpC phenotype. J. Antimicrob. Chemother. 65:460-464.

37. Kluytmans, J.A., I.T. Overdevest, I. Willemsen, M.F. Kluytmans-van den Bergh, K. van der Zwaluw, M. Heck, M. Rijnsburger, C.M. Vandenbroucke-Grauls, P.H. Savelkoul, B.D. Johnston, D. Gordon, and J.R. Johnson. 2013. Extended-spectrum $\beta$-lactamase-producing Escherichia coli from retail chicken meat and humans: comparison of strains, plasmids, resistance genes, and virulence factors. Clin. Infect. Dis. 56:478-487.

38. Kobayashi, H., J. Shimada, M. Nakazawa, T. Morozumi, T. Pohjanvirta, S. Pelkonen, and K. Yamamoto. 2001. Prevalence and characteristics of shiga toxin-producing Escherichia coli from healthy cattle in Japan. Appl. Environ. Microbiol. 67:484-489.

39. Leverstein-van Hall, M.A., C.M. Dierikx, S.J. Cohen, G.M. Voets, M.P. van den Munckhof, A. van EssenZandbergen, T. Platteel, A.C. Fluit, N. van de SandeBruinsma, J. Scharinga, M.J. Bonten, D.J. Mevius; National ESBL Surveillance Group. 2011. Dutch patients, retail chicken meat and poultry share the same ESBL genes, plasmids and strains. Clin. Microbiol. Infect. 17:873-880.

40. Liebana, E., A. Carattoli, T.M. Coque, H. Hasman, A.P. Magiorakos, D. Mevius, L. Peixe, L. Poirel, G. Schuepbach-Regula, K. Torneke, J. Torren-Edo, C. Torres, and J. Threlfall. 2013. Public health risks of enterobacterial isolates producing extended-spectrum $\beta$-lactamases or AmpC $\beta$-lactamases in food and food-producing animals: an EU perspective of epidemiology, analytical methods, risk factors, and control options. Clin. Infect. Dis. 56:1030-1037.

41. Livermore, D.M. 2012. Current epidemiology and growing resistance of gram-negative pathogens. Korean J. Intern. Med. 27:128-142.

42. Nguyen, Y., and V. Sperandio. 2012. Enterohemorrhagic E. coli (EHEC) pathogenesis. Front. Cell. Infect. Microbiol. 2:90.

43. Oh, J.Y., M.S. Kang, H. Yoon, H.W. Choi, B.K. An, E.G. Shin, Y.J. Kim, M.J. Kim, J.H. Kwon, and Y.K. Kwon. 2012. The embryo lethality of Escherichia coli isolates and its relationship to the presence of virulenceassociated genes. Poult. Sci. 91:370-375.

44. Pfeifer, Y., A. Cullik, and W. Witte. 2010. Resistance to cephalosporins and carbapenems in Gram-negative bacterial pathogens. Int. J. Med. Microbiol. 300:371-379.

45. Pitout, J.D., and K.B. Laupland. 2008. Extended-spectrum $\beta$-lactamase-producing Enterobacteriaceae: an emerging public-health concern. Lancet Infect. Dis. 8:159-166.

46. Rogers, B.A., H.E. Sidjabat, and D.L. Paterson. 2011. Escherichia coli O25b-ST131: a pandemic, multiresistant, community-associated strain. J. Antimicrob. Chemother. 66:1-14.

47. Sambrook, J., E.F. Fritsch, and T. Maniatis. 1989. Molecular Cloning: A Laboratory Manual. Cold Spring Harbor Laboratory Press, New York.

48. Seiffert, S.N., M. Hilty, A. Kronenberg, S. Droz, V. Perreten, and A. Endimiani. 2013. Extended-spectrum cephalosporin-resistant Escherichia coli in community, specialized outpatient clinic and hospital settings in Switzerland. J. Antimicrob. Chemother. 68:2249-2254.

49. Seiffert, S.N., M. Hilty, V. Perreten, and A. Endimiani. 2013. Extended-spectrum cephalosporin-resistant Gramnegative organisms in livestock: an emerging problem for human health? Drug Resist. Updat. 16:22-45. 
50. Seiffert, S.N., R. Tinguely, A. Lupo, C. Neuwirth, V. Perreten, and A. Endimiani. 2013. High prevalence of extendedspectrum cephalosporin-resistant enterobacteriaceae in poultry meat in Switzerland: emergence of CMY-2- and VEB-6-possessing Proteus mirabilis. Antimicrob. Agents Chemother. 57:6406.

51. Silva, E., S. Leitão, T. Tenreiro, C. Pomba, T. Nunes, d.C. Lopes, and L. Mateus. 2009. Genomic and phenotypic characterization of Escherichia coli isolates recovered from the uterus of puerperal dairy cows. J. Dairy Sci. 92: 6000-6010.

52. Stewardson, A.J., G. Renzi, N. Maury, C. Vaudaux, C. Brossier, E. Fritsch, D. Pittet, M. Heck, K. van der Zwaluw, E.A. Reuland, T. van de Laar, E. Snelders, C. Vandenbroucke-Grauls, J. Kluytmans, P. Edder, J. Schrenzel, and S. Harbarth. 2014. Extended-spectrum $\beta$-lactamase-producing Enterobacteriaceae in hospital food: a risk assessment. Infect. Control Hosp. Epidemiol. 35:375-383.

53. van Hoek, A.H., D. Mevius, B. Guerra, P. Mullany, A.P. Roberts, and H.J. Aarts. 2011. Acquired antibiotic resistance genes: an overview. Front. Microbiol. 2:203.

54. Voets, G.M., A.C. Fluit, J. Scharringa, C. Schapendonk, T. van den Munckhof, M.A. Leverstein-van Hall, and
J.C. Stuart. 2013. Identical plasmid AmpC $\beta$-lactamase genes and plasmid types in E. coli isolates from patients and poultry meat in the Netherlands. Int. J. Food. Microbiol. 167:359-362.

55. Welinder-Olsson, C., and B. Kaijser. 2005. Enterohemorrhagic Escherichia coli (EHEC). Scand. J. Infect. Dis. 37:405-416.

56. Wirth, T., D. Falush, R. Lan, F. Colles, P. Mensa, L.H. Wieler, H. Karch, P.R. Reeves, M.C. Maiden, H. Ochman, and M. Achtman. 2006. Sex and virulence in Escherichia coli: an evolutionary perspective. Mol. Microbiol. 60:1136-1151.

Address correspondence to: Vincent Perreten, PhD

Vetsuisse Faculty Institute of Veterinary Bacteriology

University of Bern

Länggass-Strasse 122

CH-3012 Bern

Switzerland

E-mail: vincent.perreten@vetsuisse.unibe.ch 